\title{
Profile of Caesarean Section in Mid-Western Regional Hospital in Nepal
}

\author{
Keshar Bahadur Dhakal, ${ }^{1}$ Sulochana Dhakal, ${ }^{2}$ Saroj Bhandari ${ }^{3}$
}

1'Department of Obstetrics and Gynecology, Mid-Western Regional Hospital, Surkhet, Nepal, ${ }^{2}$ National Health Service, Scotland, United Kingdom, ${ }^{3}$ Department of Public Health, Nobel College, Sinamangal, Kathmandu, Nepal.

\section{ABSTRACT}

Background: Rising rate of caesarean section since few decades has been a global public health issue. This study is
aimed to determine the rate of caesarean section plus examine the indications and complications of caesarean section.
Methods: A retrospective cross-sectional study was conducted using secondary data sources at Mid-Western
Regional Hospital in Surkhet, Nepal. Data were collected from patients'records ofthe hospital dating from 16 July
2016 to 15 July 2017 . All patients who had delivered their baby by caesarean section were included in this study. Data
were analyzed by help of SPSS version 21. Ethical approval was obtained from the hospital authority prior to the study.
Results: During the study, out of total 3,694 deliveries, $695(18.8 \%)$ were caesarean section. Most of the caesarean
section were emergency than elective $(83.0 \%$ vs $17.0 \%)$. Among all women who underwent caesarean section,
majority were from 37 to 42 weeks pregnancy $(88.5 \%)$ age group between 20 and 24 (42.9\%) and multiparous
(53.5\%).Fetal distress ( $20.1 \%)$ was most common among all major indications of caesarean section. Maternal
complications due to caesarean section was low (3.7\%). Among all complications, Post-partum hemorrhage (30.5\%)
was the major maternal complication of caesarean section. Most of newborn babies had APGAR score six or more at
one minute ( $94.5 \%)$ and five minutes ( $97.9 \%)$.
Conclusions: In our study, caesarean section rate was $18.8 \%$, which is higher than WHO recommendation (10 -
$15 \%)$. Main indication for caesarean section was fetal distress. Maternal and fetal complications were low.
Keywords: Caesarean section(CS); CS complications; CS indication.

INTRODUCTION

Cesarean section (CS) is a life-saving surgical procedure. WHO recommended CS rate is $10-15 \% .^{1}$ However, the rate of CS has been increased dramatically worldwide since few decades particularly in middle and high-income countries. ${ }^{2-5}$ Evidences have emphasized that CS should be performed only in medical indications. ${ }^{5,6}$ High rate of CS is positively associated with postpartum antibiotic treatment and severe maternal and child morbidity and mortality. 2,5,6 In developing countries, like Nepal, local health system in remote areas is still facing major challenges to provide safe and timely CS procedure which can save life of both mother and fetus. ${ }^{7}$ Rate of CS is still low in rural areas of Nepal. ${ }^{8,9}$ However, rate of CS is high in urban areas of Nepal. ${ }^{10-12}$ Private facilities and better education of women can be attributed for rising rate of CS in urban settings. ${ }^{13}$ This study has explored the rate, indications and complications of CS in Mid-Western Regional Hospital in Nepal.

\section{METHODS}

A retrospective cross-sectional study was carried out using secondary data at the referral level Mid-Western Regional Hospital, Surkhet, Nepal. Data were collected from hospital records dating from 16 July 2016 to 15 July 2017. Data were extracted from hospital medical record and case files. Data were coded and edited prior to its entry and analysis through Statistical Package for Social Sciences (SPSS) version 21.0.

All deliveries conducted during the study period were included in this study. Among them, specific profile was created for those who delivered their babies by CS. Modes of delivery, types and frequency of caesarean section, indications, and complications of caesarean section were recorded along with demographic data such as age, ethnicity, place of residence, parity, and gestational age. Proportion and percentages were calculated and compared. 


\section{RESULTS}

Table 1 represents the distribution of caesarean section rate. Total of 3,694 deliveries conducted during the study period. Among the total deliveries,695 (18.8\%) women had delivered their baby by caesarean section. It was found that majority of the women $(83 \%)$ had emergency caesarean section. Likewise, majority of the women $(84.5 \%)$ had primary caesarean section.

\begin{tabular}{lrr}
$\begin{array}{l}\text { Table 1. Distribution of caesarean section rate. } \\
(\mathrm{n}=695) .\end{array}$ & $\begin{array}{r}\text { No. of } \\
\text { Patients }\end{array}$ & \\
\hline Modes of delivery & 2999 & 81.5 \\
\hline Vaginal delivery & 695 & 18.8 \\
\hline Caesarean section & & \\
\hline Types of caesarean section & 577 & 83.0 \\
\hline Emergency & 118 & 17.0 \\
\hline Elective & & \\
\hline Frequency of caesarean section & 597 & 84.5 \\
\hline Primary & 108 & 15.5 \\
\hline Repeated & & \\
\hline
\end{tabular}

Table no. 2 depicts the distribution of demographic characteristics of the women who were conducted CS delivery. It was found that nearly half of the women were between the age group of 20 and 24 years (42.9\%). Similarly, more than half women were multipara/ gravida $(53.5 \%)$ and most of them had gestational age of 37 or more weeks (94.4\%) among total women who were conducted CS delivery respectively. Likewise, majority of the women were from Surkhet district $(79.9 \%)$ and as per ethnicity of the women, nearly six out of ten were Brahmin/Chhetri (58.4\%) among total women who were conducted CS delivery. Table 2. Demographic characteristics of women who underwent caesarean section.

\begin{tabular}{l} 
Subjects $\begin{array}{r}\text { No. of } \\
\text { Patients }\end{array}$ \\
\hline
\end{tabular}

\begin{tabular}{lrr}
\hline Age $(\mathrm{n}=695)$ & & \\
$<19$ or 19 & 107 & 15.4 \\
$20-24$ & 298 & 42.9 \\
\hline $25-29$ & 192 & 27.6 \\
$30-34$ & 75 & 10.8 \\
$>35$ & 23 & 3.3 \\
Antenatal Care $(\mathrm{n}=675)$ & & \\
Booked & 330 & 48.9 \\
Self & 281 & 41.6 \\
\hline Referred & 64 & 9.5
\end{tabular}

\begin{tabular}{lrr}
\hline Parity/Gravida $(\mathbf{n = 6 9 5 )}$ & 323 & 46.5 \\
\hline Primi & 372 & 53.5 \\
\hline Multi & & \\
\hline Place of Residence $(\mathrm{n}=695)$ & 555 & 79.9 \\
\hline Surkhet District & 140 & 20.1 \\
\hline Other Districts & & \\
\hline Gestational age $(\mathrm{n}=695)$ & 39 & 5.7 \\
\hline Preterm (<37 weeks) & 615 & 88.5 \\
\hline Term (37 - 42 weeks) & 41 & 5.9 \\
\hline Post Term (>42 weeks) & & \\
\hline Ethnicity & 406 & 58.4 \\
\hline Brahmin/Chhetri & 152 & 21.0 \\
\hline Janajati & 137 & 19.7 \\
\hline Minority/Dalit & & \\
\hline
\end{tabular}

Table 3 shows the distribution of indications of caesarean section. It was found that among total CS delivered women, major indication for CS delivery was fetal distress $(20.1 \%)$ followed by previous CS (17.8\%), meconium stained liquor $(17.7 \%)$, non-progress of labor (17.1\%) and breech/malpresentation (15.8\%) respectively.

Table 3. Indications of caesarean section. $(n=695)$.

\begin{tabular}{lrr}
\hline Indications & No. of Patients & $\%$ \\
\hline Fetal distress & 140 & 20.1 \\
\hline Previous CS & 124 & 17.8 \\
\hline Meconium stained liquor & 123 & 17.7 \\
\hline Non-progress of labor & 119 & 17.1 \\
\hline Breech/malpresentation & 110 & 15.8 \\
\hline Failed vacuum/ & 16 & 2.3 \\
instrumental & & \\
\hline Obstructed labor & 15 & 2.2 \\
\hline Eclampsia & 14 & 2.0 \\
\hline APH/placenta previa & 14 & 2.0 \\
\hline Failed induction & 12 & 1.7 \\
\hline Oligohydramnios & 1 & .1 \\
\hline Other & 7 & 1.0 \\
\hline
\end{tabular}

Furthermore, the main indications of emergency caesarean section were fetal distress $(24.3 \%, n=140)$, meconium stained liquor $(21.3 \%, n=123)$, non-progress of labor(20.6\%, $n=119)$ and breech/malpresentation $(13.3 \%, n=77)$. Similarly, the main indications of elective caesarean section were previous caesarean section (61.9\%, $n=73)$ and breech/malpresentation (28.0\%, $n=33)$. 
Out of 695 caesarean section cases, only 26 (3.7\%) mothers had complications in this study. The main complication was post-partum hemorrhage (Table 4).

Table 4 represents the distribution of maternal complications. Among total CS delivered women who had maternal complications, most of them had postpartum hemorrhage $(30.8 \%)$ whereas only $3.8 \%$ had wound infection and its consequences.

\begin{tabular}{lrr}
$\begin{array}{l}\text { Table 4. Distribution of maternal complications. } \\
\text { (n=26). }\end{array}$ & $\begin{array}{r}\text { No. of } \\
\text { patients }\end{array}$ \\
\hline Complications & 8 & 30.8 \\
\hline Post-partum hemorrhage(PPH) & 3 & 11.3 \\
\hline Shock & 5 & 19.2 \\
\hline Injury to the surrounding structure & 1 & 3.8 \\
Wound infection and its & & \\
consequences & 4 & 15.3 \\
\hline Sepsis/systemic infection & 5 & 19.2 \\
\hline Mastitis/breast infection & & \\
\hline
\end{tabular}

Table 5 reveals the distribution of APGAR score of newborn babies in one minute and five minutes respectively. It was found that most of the newborn babies had APGAR score of six or more both within one minute (94.5\%) and within five minutes (97.9\%).

Table 5. APGAR score of newborn babies in one minute and five minutes. $(n=677)$.

\begin{tabular}{lllll} 
APGAR score & \multicolumn{2}{c}{ One minute } & \multicolumn{2}{c}{ Five minutes } \\
& $\mathrm{n}$ & $\%$ & $\mathrm{n}$ & $\%$ \\
\hline 0 & 9 & 1.3 & 9 & 1.3 \\
$<6$ & 28 & 4.1 & 5 & 0.7 \\
6 or more & 640 & 94.5 & 663 & 97.9 \\
\hline
\end{tabular}

\section{DISCUSSION}

Growing rate of CS is a matter of concern everywhere in the world. Although, CS is a safe obstetric surgical procedure, increasing trend of CS rate has been a worrying issue in Nepal. ${ }^{8,10,14,15}$ Some studies have shown a very high rate of CS in urban and private settings in Nepal. ${ }^{12,15,16}$ CS rate higher than the WHO recommendation (10-15\%) is not justified medically. ${ }^{1}$ High rate of CS can cause significant adverse effects on maternal and child health. CS performed only in medically indicated situation can save lives and prevent maternal and perinatal mortality and morbidity. ${ }^{17}$

In our study, CS rate was $18.8 \%$ of total deliveries.CS rate of our study issame as the study finding(19.89\%) of Subedi S. ${ }^{11}$ Likewise, our result is close to the study conducted by Suwal et al $(22.30 \%)$ in Nepal Medical College Teaching Hospital ${ }^{18}$ and another study by Kumbo et al $(21.8 \%)$ in India. ${ }^{19}$ CS rate of our study is higher than the study conducted by Samdal et al (9.5\%)in rural Nepal. ${ }^{9}$ However, the CS rate in our study is lower than other studies conducted in Nepal, such as: CS rate 45.81\% reported by Prasad et al in Kathmandu Medical College, ${ }^{12} 41.9 \%$ by Pradhan et al in Patan hospital ${ }^{15}$ and $50.9 \%$ by Pradhan et al in Kirtipur hospital. ${ }^{16}$ Similarly, the CS rate in our study is lower than $31.46 \%$ reported by Gupta et al in Jaipur, India ${ }^{20}$ and $36.6 \%$ in study by Sreevidya et al in Madras, India. ${ }^{21}$

Our study has found high rate of emergency $\mathrm{CS}(83 \%)$ as found in other studies..$^{9,12,19}$ However, the percentage of emergency CS in our study seems to be the highest than all those studies. 9,12,15,16,19,20 Mid-Western Regional Hospital is a referral center in Mid-Western Regionof Nepal which correlates to high emergency CS rate. Frequency of primary CS was high (84.5\%) and it is higher than reported by other studies. ${ }^{11,20}$ Majority of multipara women, full term pregnancy and age group 20-24 were undergone CS in this study as described by Gupta et al. ${ }^{20}$ About $15.4 \%$ of adolescent group had delivered baby by CS in this study which is higher than $3.23 \%$ reported by Gupta et $\mathrm{al}^{20}$ and $4.7 \%$ by Pradhan et al. ${ }^{16}$ Antenatal booked cases were lower (48.9\%) in our study as compared to Pradhan et al (85.3\%) ${ }^{16}$ and Gupta et al $(68.31 \%)^{20}$. Brahmin/Chhetri ethnicity and women residing in Surkhet district had more access to CS. It may be due to high population of Brahmin/Chhetri ethnicity and the hospital is situated in Surkhet.

Fetal distress was the first leading indication for CS in our study accounting for $20.1 \%$ as found in other studies. ${ }^{11,16,18}$ However, it is lower as compared to $26.25 \%$ reported by Subedi ${ }^{11}$ and $40.2 \%$ reported by Pradhan et al. ${ }^{16}$ Many other studies also described that fetal distressis a common cause of CS. 9,12,15,19,20,22 In fact, fetal distress was found to be number one indication for emergency CS as defined by Suwal et al. ${ }^{18}$ However, the gold standard method of estimation of fetal distress Fetal scalp PH estimation was not performed to identify fetal distress in our study.

In our study, previous CS (17.8\%) was second common indication of CS as defined in other studies. ${ }^{10,11.15 .18}$ However, Prasad et al (21.3\%) and Gupta et al (36.52\%) reported previous CS is the leading indication of CS. ${ }^{12,16,20}$ Some other studies also identified previous CS as a common cause of CS. ${ }^{10,22}$ Previous CS was the key indication of elective CS in our study as reported by Suwal et al. ${ }^{18}$ Due to lack of information about patients 
Profile of Caesarean Section in Mid-Western Regional Hospital in Nepal

and some other reasons, practice trial for vaginal birth after caesarean section (VBAC) is less in Mid-Western Regional Hospital. Evidence has shown that women with history of previous CS can refuse the trial due to the complications such as scar dehiscence and rupture. Sharma et al reported $48.38 \%$ (15 out of 31 ) was refusal of trial of scar. ${ }^{23}$ Although, VBAC is safer than repeat CS but not doctor friendly. ${ }^{24}$

Third leading cause of CS was meconium stained liquor $(17.7 \%)$ in our study. It is higher than the study conducted in Patan hospital $(12.3 \%)^{15}$ and Kathmandu Medical College $(9.6 \%)^{12}$ but lower than study conducted in Eastern Nepal (23.4\%). ${ }^{10}$ Similarly, the fourth common reason of CS was non-progress. Many other studies have shown same reason for performing CS. ${ }^{10-12,15,16,18,23}$ The fifth common reason of performing CS was breech/ malpresentation $(15.8 \%)$ in our study. Many other studies also have recognized it as a significant cause of CS. ${ }^{9}$ $12,15,16,18,22,23$

High rate of CS can be the cause of maternal morbidity and mortality. Evidences have shown an association between CS and maternal complications. ${ }^{2,5,6}$ In our study, no any maternal mortality observed, and overall maternal morbidity rate was $3.7 \%$, which is lower than reported by Pradhan et al $(7.2 \%)^{16}$ and Gupta et al $(10.60 \%) .{ }^{20}$ The main complication was post-partum hemorrhage (PPH) in our study, accounting $30.8 \%$, which is higher than showed by $20.8 \%$ in Pradhan et al. ${ }^{16} \mathrm{PPH}$ is identified significant maternal complication in elective CS. ${ }^{18}$ Another complication was injury to surrounding structure $(19.2 \%)$ in this study. Gupta et $\mathrm{al}^{20}$ also found minor bladder injury as a major complication of CS. Mastitis/breast (19.2\%) infection also noticed as a common complication in our study as described in Pradhan et al. ${ }^{16}$ Sepsis and systemic infection (15.3\%) also found a maternal problem of CS in our study.

Increase CS rate not only associated with maternal complications but also found to be associated with fetal mortality and morbidity. ${ }^{6}$ In our study, most of new born babies'APGAR score at one minute $(92.1 \%)$ and five minutes $(97,4 \%)$ was good.A study conducted by Pradhan et $\mathrm{al}^{16}$ had similar APGAR score $(93.2 \%)$ in one minute and $99.2 \%$ in five minutes). However, there was $1.3 \%(n=9)$ newborn babies had APGAR score 0 , which refers no signs of life. There were $4.1 \%(n=28)$ newborn babies had APGAR score $<6$ at one minute, which means poor health and require medical assistance and close observation.

The study was not able to cover large scale data due to lack of enough resources such as time, funding.
Unfortunately, some data were missing because of incomplete records. Therefore, the study findings may be limited.

\section{CONCLUSIONS}

Caesarean section rate was high in this study. The main indications of CS were fetal distress, previous CS, meconium stained liquor, non-progress of labor and breech/malpresentation. Maternal and neonatal complications of CS were low. Effective obstetric management by following standardized guidelines can reduce the rate of $\mathrm{CS}$.

\section{ACKNOWLEDGEMENTS}

Our sincere thanks to Prof. Dr. Ganesh Dangal for providing us valuable advice and guidance on concept, design, conduction and critical review of the study. We would like to express thanks to medical superintendent, medical record and all staff of Mid-Western Regional hospital for their help in our study.

\section{REFERENCES}

1. World Health Organization. Appropriate technology for birth. Lancet. 1985;326(8452):436-7. [PubMed, Seience Direct]

2. Lumbiganon $P$, Laopaiboon M, Gülmezoglu AM, Souza J, Taneepanichskul S, Ruyan P, et al. World Health Organization Global Survey on Maternal and Perinatal Health Research Group. Method of delivery and pregnancy outcomes in Asia: the WHO global survey on maternal and perinatal health 2007-08. Lancet. 2010;375(9713):490-9. [PubMed]

3. Betrán AP, Merialdi M, Lauer JA, Bing-Shun W, Thomas J, Van Look P, et al. Rates of caesarean section: analysis of global, regional and national estimates. Paediatr Perinat Epidemiol. 2007;21(2):98-113. Google Scholar]

4. Betrán AP,Ye J, Moller A-B, Zhang J, Gülmezoglu AM, Torloni MR. The increasing trend in caesarean section rates: global, regional and national estimates: 1990-2014. PloS ONE. 2016;11(2):e0148343.[Google Scholar]

5. Souza JP, Gülmezoglu AM, Lumbiganon P, Laopaiboon M, Carroli G, Fawole B, Ruyan P. Caesarean section without medical indications is associated with an increased risk of adverse short-term maternal outcomes: the 2004-2008 WHO Global Survey on Maternal and Perinatal Health. BMC Med. 2010;8(1):71.[Full Text]

6. Villar J, Valladares E, Wojdyla D, Zavaleta N, Carroli G, 
Velazco A, Shah A, Campodónico L, Bataglia V, Faundes A, Langer A. Caesarean delivery rates and pregnancy outcomes: the 2005 WHO global survey on maternal and perinatal health in Latin America. Lancet. 2006;367(9525):1819-29. [Science Direct]

7. Ronsmans C, Holtz S, Stanton C. Socioeconomic differentials in caesarean rates in developing countries: a retrospective analysis. Lancet. 2006;368(9546):1516-23. [Science Direct]

8. Prakash K, Neupane S. Caesarean deliveries among Nepalese mothers: changes over time 2001-2011 and determinants. Arch Gynecol Obstet. 2014;289(2):421-7.[Full Text]

9. Samdal LJ, Steinsvik KR, Pun P, Dani P, Roald B, StrayPedersen B, Bøhler E. Indications for Cesarean Sections in Rural Nepal. J Obstet Gynecol India. 2016;66(1):284-8. [Full Text]

10. Chhetri S, Singh U. Caesarean section: its rates and indications at a tertiary referral center in Eastern Nepal. Health Renaissance. 2011;9(3):179-83. [Fulltext]

11. Subedi S. Rising rate of caesarean section-a year review. Journal of Nobel Medical College. 2012;1(2):50-6. [Full Text]

12. Prasad A, Bhandari G, Saha R. Profile of Caesarean Section at Kathmandu Medical College. J Nepal Health Res Counc. 2017;15(2):110-3. [JNHRC]

13. Neuman M, Alcock G, Azad K, Kuddus A, Osrin D, More NS, Nair N, Tripathy P, Sikorski C, Saville N, Sen A. Prevalence and determinants of caesarean section in private and public health facilities in underserved South Asian communities: cross-sectional analysis of data from Bangladesh, India and Nepal. BMJ Open. 2014;4(12):e005982.[Full Text]

14. Amatya A, Paudel R, Poudyal A, Wagle RR, Singh M, Thapa $\mathrm{S}$. Examining stratified cesarean section rates using Robson classification system at Tribhuvan University Teaching Hospital. J Nepal Health Res Counc. 2013;11(25):255-8. [PubMed] [JNHRC]
15. Pradhan B, Shrestha SD, RC L, Sharma P, Bhandary S. Increasing Trend of Caesarean Section in Patan Hospital. Journal of General Practice and Emergency Medicine of Nepal. 2015; 4(6):3-5.[Full Text]

16. Pradhan P, Shrestha S, Rajbhandari P, Dangal G. Profile of Caesarean Section in Kirtipur Hospital. Nepal Journal of Obstetrics and Gynaecology. 2014;9(2):51-4. [Full Text]

17. Betran A, Torloni M, Zhang J, Gülmezoglu A. WHO Statement on caesarean section rates. BJOG. 2016;123(5):66770. [Full Text]

18. Suwal A, Shrivastava VR, Giri A. Maternal and fetal outcome in elective versus emergency caesarean section. J Nepal Med Assoc. 2013;52(192). [Full Text]

19. Kambo I, Bedi N, Dhillon B, Saxena N. A critical appraisal of caesarean section rates at teaching hospitals in India. Int J Gynecol Obstet. 2002;79(2):151-8. [Full Text]

20. Gupta M, Garg V. The rate and indications of caesarean section in a tertiary care hospital at Jaipur, India. International Int J Reprod Contracept Obstet Gynecol. 2017;6(5):178692. [FullText]

21. Sreevidya S, Sathiyasekaran B. High caesarean rates in Madras (India): a population-based cross sectional study. BJOG. 2003;110(2):106-11. [Full Text]

22. Leitch $\mathrm{C}$, Walker J. The rise in caesarean section rate: the same indications but a lower threshold. BJOG. 1998;105(6):621-6. [Full Text]

23. Sharma A, Acharya R, Sharma U, Chaudhary A, Chaudhary P, Hanspal J. Maternal and Neonatal Outcome in Patients with History of Previous One Caesarean Section. Ind Med Gaz. 2012:169-173.. [Full Text]

24. Wagner M. Choosing caesarean section. Lancet. 2000;356(9242):1677-80. [Full Text] 